\title{
Dinâmica geoambiental das Planícies Fluviais e Lacustres de Rio do Fogo/RN (Brasil)
}

\author{
Dynamic geoambiental of the Plains Riverines and Lacustrines of Rio do Fogo/RN (Brazil)
}

\author{
LOUZEIRO $^{1}$, A. S.; CAMARA ${ }^{2}$, M. R.; ROSA ${ }^{3}$, E. M.; CESTARO ${ }^{4}$, L. A. \\ andreza_louzeiro@hotmail.com
}

\begin{abstract}
Resumo
É fundamental o entendimento da formação de elementos físicos de um determinado local para a compreensão da sua dinâmica ambiental. Sabendo disto, pesquisas sobre estudos de caso são uma importante ferramenta para que esse tipo de análise seja feito. Neste sentido, o presente trabalho tem como objetivo demonstrar as interações Geoambientais existentes entre os elementos físicos e antrópicos presentes no município de Rio do Fogo/RN (Brasil) e ainda a relação que a Planície Costeira e o Tabuleiro Costeiro possuem com as Planícies Fluvial e Lacustre da referida área de estudo. Para tanto, foi necessário o embasamento da abordagem geossistêmica para subsidiar a inter-relação existente entre $o$ fator natural e antrópico, bem como a utilização de geotecnologias para a elaboração dos mapas. Sendo assim, o resultado desta pesquisa foi essencial para perceber que as Planícies Fluvial e Lacustres de Rio do Fogo/RN são áreas de extrema dinâmica ambiental, seja com interação com os elementos de fator exógeno, seja endógeno.
\end{abstract}

Palavras-chave: Planícies Fluvial e Lacustre. Interação. Rio do Fogo/RN (RN-Brasil)

\begin{abstract}
Is fundamental the understanding of the interaction of the physical elements of a determined local for the understanding of their environmental dynamic. Case studies are an important tool to this type of analysis be it made. In this sense, the present work aims to analyze the interactions geoenvironmental existing between the physical elements and anthropic present in the municipality of Rio do Fogo (RN - Brazil) and still the relation that the Coastal Plain and the Coastal Tableland have with the Plains Riverine and Lacustrine of referred to study area. For both, it was necessary the basement of geosystemic approach to subsidize the interrelationship existing between the natural factor and the anthropic, as well as use of geotechnologies for the elaboration of maps. Thus, the result of this research was essencial to perceive that the as Plains Riverine and Lacustrine of Rio do Fogo are areas of high environmental dynamic, whether in function of the elements associated with factors exogenous, whether endogenous.
\end{abstract}

Keywords: Plains Riverine and Lacustrine; Interaction; Rio do Fogo (RN - Brazil).

\section{INTRODUÇÃO}

O entendimento dos sistemas ambientais é fundamental para a compreensão da influência dos atributos físicos na dinâmica natural de uma determinada área. Sabendo disto, cabe destacar que, segundo Calderano Filho (2012) o estudo geoambiental auxilia no que diz respeito a delimitação de áras que devem apresentar certa homogeneidade interna em função das variáveis ambientais.

\footnotetext{
${ }^{1}$ Andreza dos Santos Louzeiro, aluna do Programa de Pós Graduação em Geografia, Universidade Federal do Rio Grande do Norte, Natal-RN, Brasil.

${ }^{2}$ Michel Rodrigues Camara, aluno do Programa de Pós Graduação em Engenharia Civil, Universidade Federal do Rio Grande do Norte, Natal-RN, Brasil.

${ }^{3}$ Eliezer Mazzetti Rosa, aluno do Programa de Pós Graduação em Geografia, Universidade Federal do Rio Grande do Norte, NatalRN, Brasil.

${ }^{4}$ Luiz Antonio Cestaro, professor do Departamento de Geografia, Universidade Federal do Rio Grande do Norte, Natal-RN, Brasil.
} 
A relação sociedade-natureza nesse espaço é importante no que diz respeito à sua sustentabilidade ambiental e à manutenção dos recursos naturais originados deste tipo de ambiente para que desta forma possa haver uma interação consonante tanto para o ser humano quanto para a natureza. Para que isso ocorra é necessário o conhecimento técnico-científico das potencialidades e fragilidades naturais nas unidades geoambientais e, posteriormente, fazer o uso ou não dos seus atributos.

O território brasileiro possui uma infinidade de formas geomorfológicas, vegetacionais distintas e cada uma apresenta uma dinâmica particular. Uma das unidades que cabe destaque nesta pesquisa são as Planícies Fluviais e Lacustres situadas no município de Rio do Fogo/RN. Além destas unidades, o município em questão possui também Planície Costeira e Tabuleiros, onde a interação entre estas unidades resultam em consideráveis influências uns sobre os outros.

Neste sentido, o presente trabalho tem como objetivo demonstrar as interações geoambientais existentes entre os elementos físicos e antrópicos presentes no município de Rio do Fogo/RN e ainda a relação que a Planície Costeira e o Tabuleiro Costeiro possuem com as Planícies Fluvial e Lacustre da referida área de estudo.

\section{METODOLOGIA}

Para dar sustentação a esse estudo, a abordagem geossistêmica torna-se fundamental, pois através dela obtêm-se combinações dinâmicas dos elementos físicos, biológicos e antrópicos da paisagem. Segundo Monteiro (2001), a aplicação dos estudos geossistêmicos auxiliam nas estruturas dos subsistemas, através de uma hierarquia da dinâmica espacial, ambiental e social, que apresentam caráter vertical e horizontal, desempenhando a análise geográfica de forma estruturada e gradual.

O conceito de geossistema criado por Sotchava (1977), incorpora a dimensão da ação antrópica, sendo uma categoria espacial de componentes relativamente homogêneos, cuja dinâmica resulta da interação entre o potencial ecológico, a exploração biológica e a ação antrópica. Sendo assim, esta abordagem será empregada na análise da dinâmica do ambiente e subsidiará a compreensão da relação homem-ambiente.

O geossistema deve ser visto de maneira mais abrangente do que o ecossistema nos estudos geográficos, por incluir a dimensão espacial de forma mais nítida. Ele permite uma compatibilidade a mais do que o ecossistema, pois analisa as relações e a distribuição dos componentes naturais, modificados ou não pelo homem, mas que estão interligadas aos sistemas ambientais, onde a integração do todo é atribuição básica. 
O mapeamento dos solos foi anaisado com base no material disponibilizado pela EMBRAPA, onde o arquivo original foi georreferenciado e vetorizado. Já as curvas de níveis eqüidistantes de 5 metros foram obtidas das ortofotocartas para identificar as unidades geoambientais, planície fluvial e feições de duna para posterior validação em campo.

Desta forma, a partir dos arquivos vetoriais e imagens de satélite foram elaborados os mapas de localização, altimétrico e geomorfológico considerados como "Mapa Base". A partir dessa base cartográfica as unidades geoambientais foram delimitadas através da interpretação visual sobre as imagens de satélite, ortofotocartas, curvas de níveis e MDT, para posterior verificação in loco para validação, reavaliação e correções das informações contidas no mapa.

Foi feita visita in loco, nos dias 23 de maio e 14 de junho de 2016. Com uso do GPS de navegação, os arquivos vetoriais referentes às vias de acesso, comunidades, corpos hídricos e as unidades geoambientais foram carregadas no equipamento, como também, pontos pré-selecionados para esclarecer dúvidas nos locais e validar as informações contidas nos mapas.

Tais visitas proporcionaram realizar, junto aos moradores locais, a obtenção e correção da toponímia identificada na cartografia existente, tais como nomes de rios e comunidades e vias de acesso. Após as verificações, as informações coletadas contribuíram para que fossem realizadas as correções necessária nos mapas e a delimitação das unidades geoambientais de Rio do Fogo/RN.

Desta forma, com o auxílio da abordagem geossistêmica, neste trabalho ainda foram necessários a utilização de alguns procedimentos metodológicos ilustrados na Figura 01.

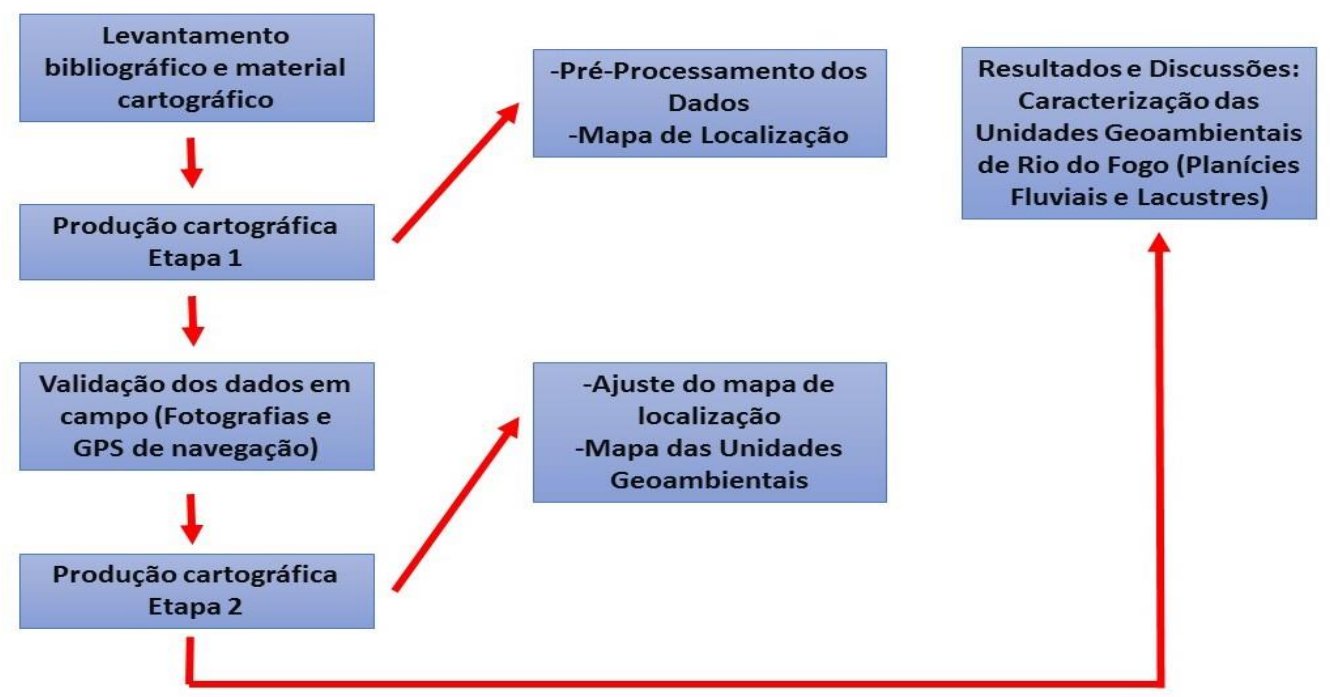

Figura 01: Percurso metodológico para caracterização das unidades geoambientais do município de Rio do Fogo/RN.

Fonte: Elaboração dos autores, 2016.

\section{RESULTADOS E DISCUSSÃO}




\subsection{Localização e situação geográfica da área de estudo}

O município de Rio do Fogo/RN possui $150,4 \mathrm{~km}^{2}$ de área territorial e localiza-se no litoral leste do estado do Rio Grande do Norte, na microrregião litoral nordeste, limitando-se com o município de Touros ao Norte, Pureza à Oeste, Maxaranguape ao Sul e o Oceano Atlântico à Leste, sendo as rodovias RN-064 e a BR-101, as principais que cortam o município (Figura 2).

De acordo com o censo demográfico realizado pelo Instituto Brasileiro de Geografia e Estatística (IBGE) no ano de 2010, a população do município foi de 10.059 habitantes e estimada em 10.758 habitantes para o ano de 2015 (IBGE, 2016).

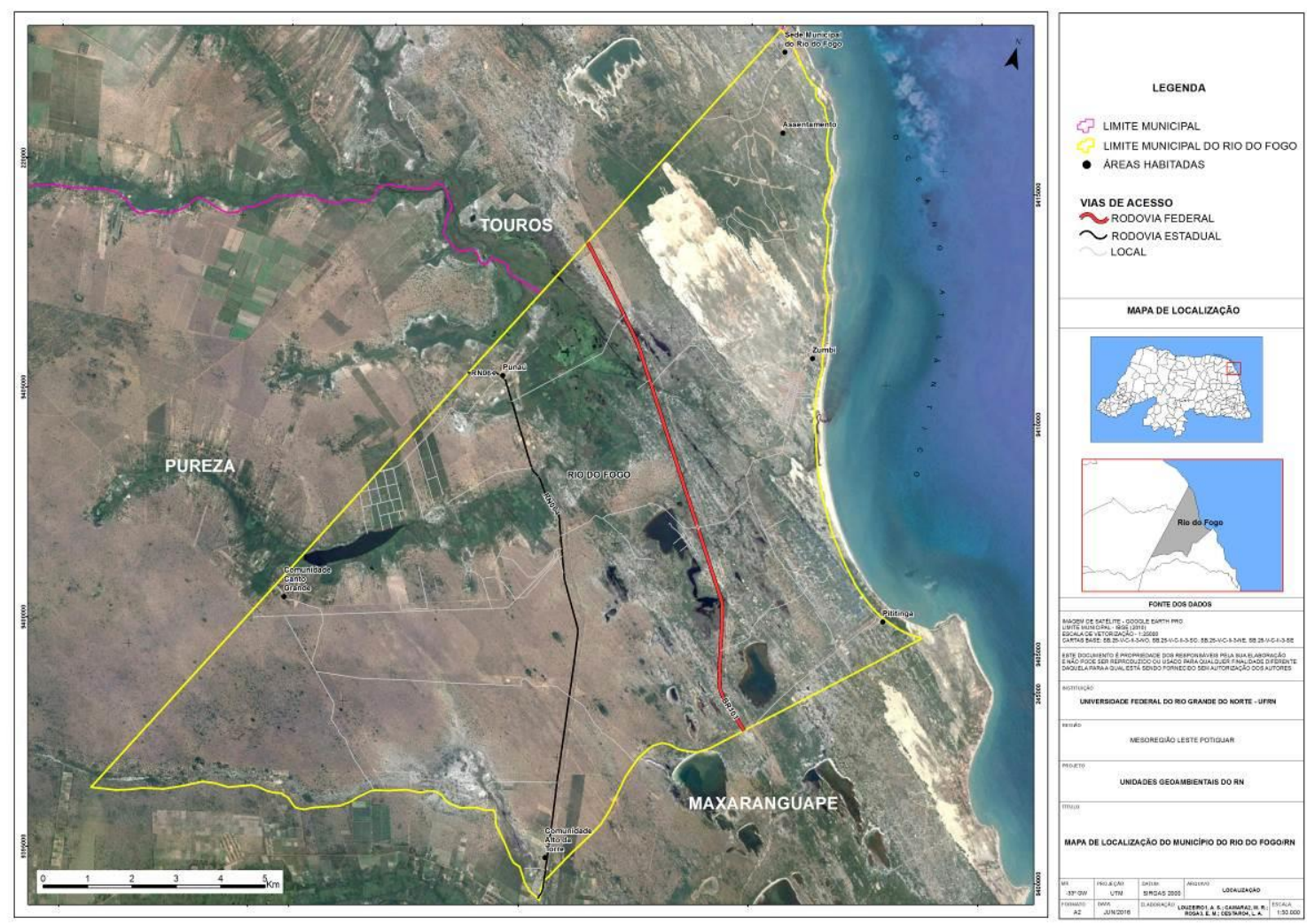

Figura 02 - Mapa de localização do município do Rio do Fogo/RN. Fonte: Elaboração Própria, 2016.

Para entender melhor a dinâmica das Planícies Fluvial e Lacustre do município de Rio do Fogo/RN, se faz necessário a conceituação de alguns elementos. Sendo eles, lagoas perenes, área de alagado, rios perenes e intermitentes, tais elementos são encontrados em toda extensão do território do município.

Segundo Suguio (1998) rio perene é aquele cujas águas fluem durante o ano inteiro, como a maioria dos cursos fluviais brasileiros, já o rio intermitente é aquele cujas águas fluem somente durante parte do ano. Nas regiões de climas áridos e semiáridos, é comum a existência deste tipo de rio. No que se refere a áreas alagadas, Burger (1999) afirma que são áreas que possui a presença de águas rasas ou solo saturado, possui acúmulo de material orgânico proveniente da vegetação e a presença de plantas e animais adaptados à vida aquática. 
De acordo com as definições de Tundisi e Tundisi (2008), lago é o nome genérico dado a toda massa de água que se acumula de forma natural numa depressão topográfica, totalmente cercada por terra. Os lagos podem ser de água doce, salobra ou salgada e variam em forma, tamanho e profundidade. Os de menor superfície são por vezes chamados lagoa, enquanto os maiores - como o Cáspio, por exemplo - recebem o nome de mar (restritos, sem ligação com o oceano).

No que se refere às Planícies Fluvial e Lacustre do município de Rio do Fogo/RN, ambas possuem uma dinâmica característica do município, portanto para compreender os processos naturais desta unidade, é interessante estabelecer a descrição desses elementos, sendo eles, geologia, geomorfologia, pedologia e vegetação.

No que se refere à Geologia, pode-se afirmar que na área da Planície Lacustre predominam paleodunas nas bordas das lagoas de maior área, devido o regime de ventos e influência da Planície Costeira. Nos rios contém depósitos de aluviões, os quais são caracterizados por possuírem sedimentos retrabalhados devido o regime dos ventos e da precipitação. Já na desembocadura dos rios predomina a formação das dunas fixas e móveis.

A Geomorfologia da Planície Fluvial no município é caracterizada por apresentar área plana, a qual é resultante da acumulação fluvial e está sujeita a inundações periódicas, sendo fator preponderante para classificar os rios perenes e intermitentes. No que se refere ao relevo da Planície Lacustre, pode-se afirmar que possuem dunas fixas, caracterizada pela presença de vegetação rasteira, as quais ajudam a movimentação mais lenta das dunas. Esses depósitos de dunas fixas são de origem marinha e são remodelados pelo regime dos ventos.

Com relação aos aspectos pedológicos da Planície Fluvial de Rio do Fogo/RN, de acordo com a nova classificação de solos, a área possui latossolos, já a Planície Lacustre é formada por neossolos e na desembocadura dos rios, pode-se afirmar que predominam os organossolos (SOUZA et al, 1981 e SANTOS et al, 2013).

Já os aspectos vegetacionais, Salgado (et al, 1981) afirma que na área da Planície Lacustre existe a influência marinha na formação das restingas e, na Planície Fluvial, a vegetação arbórea aberta sem floresta de galeria. Em campo, pode-se identificar a presença de vegetação herbácea na superfície do rio Piranhas e hidrófilas em áreas de alagado.

\subsection{Interação entre os elementos naturais e sistemas vizinhos}

Para entender a dinâmica de uma determinada área é fundamental ter um maior aprofundamento no que se refere aos aspectos físicos e antrópicos que a compõe e como esses elementos interagem entre si. Neste sentido, pode-se afirmar que Rio do Fogo/RN é beneficiado em recursos hídricos, o qual segundo Lima e Amaral (2013) o município é abrangido pelas bacias do 
rio Maxaranguape e do rio Punaú. O Punaú está inserido na bacia formada por ele e pelos rios das Piranhas, do Saco, Carro Quebrado, Tatu, das Curicacas e Córrego do Arrepiado, este rio apresenta orientação oeste-leste desaguando no litoral oriental no Oceano Atlântico e seu padrão da drenagem é do tipo dendrítico. Além disso, Rio do Fogo/RN apresenta diversas lagoas, dentre elas, as lagoas do Catolé, das Cutias, da Mutuca, Barrenta, Atoleiro e do Galego.

A primeira interação observada é entre o clima e o regime dos rios e lagos, onde é facilmente detectada tanto na influência da quantidade da vazão dos rios e lagos, como na orientação das lagoas e de áreas alagadas. A forte precipitação pluviométrica gera rios intermitentes bem desenvolvidos que mesmo nas estações de seca, seus depósitos aluviais e morfologia fluvial continuam se destacando na paisagem, é o caso do Rio D’água Colônia e suas ramificações que é utilizado para demarcar a divisão sul do referente município em estudo com o município de Maxaranguape/RN.

Nas estações de inverno, as extensas planícies de inundação dos Rios Punaú, Piranhas e das Curicacas são enriquecidas de argila, colóide e matéria orgânica por conta do transbordamento dos rios, tornando o solo mais fértil. Além do lençol freático ficar mais raso, aflorando nas planícies interdunares e deflação, sendo caracterizados por áreas alagadas. Essas áreas possuem uma morfologia intensamente controlada pelo regime dos ventos alísios, possuindo corpos alongados na direção SE-NO.

No contexto geológico e pedológico, observa-se dois tipos de depósitos no vale fluvial com características diferentes, dada a variação de comportamento do rio nos diferentes ambientes. O primeiro está no próprio canal, enquanto o outro na planície de inundação. No primeiro ocorre nítida orientação preferencial dos seixos e também das marcas que indicam deposição em águas correntes. Predominam seixos e areias entre os detritos depositados.

Já nos depósitos da planície de inundação, devido ao serpentear irregular dos rios que mudam continuamente o seu curso, a orientação dos detritos é variável, sem direção preferencial alguma, sendo mais comum a ausência de orientação dos fragmentos alongados, dada a menor velocidade da correnteza, onde a predominância dos sedimentos será de areia fina, silte e argila. No que diz respeito aos sistemas lacustres, ocorre a predominância de areia na fração fina, silte e argila com ausência de orientação predominante, devido à baixa energia e a insuficiência de águas correntes.

A geomorfologia está interagindo simultaneamente com o clima e a geologia, uma vez que a estação chuvosa intensifica a ação erosiva e intempérica das águas que vão moldando a paisagem, aplainando o relevo e redesenhando a morfologia do vale fluvial e lagunar, ao mesmo tempo em que os sedimentos são extraídos das rochas, transportados e depositados nesses sistemas. 
A vegetação das margens dos rios e lagoas, mata ciliar ou de galeria, rapidamente desenvolvese nesses ambientes devido a umidade dessas áreas, pois o lençol freático está mais raso. A fertilidade nas planícies de inundação também aumenta devido a deposição de camadas de sedimentos finos, siltes, argilas, colóides e matéria orgânica. Tal vegetação cria uma espécie de barreira no entorno desses corpos d'água, protegendo suas margens de erosão e evitando o assoreamento dos mesmos. Além disso, existe a vegetação aquática, a qual está presente na superfície (vegetação aquática herbácea) e no fundo dos rios e lagos (Figuras 03 e 04)
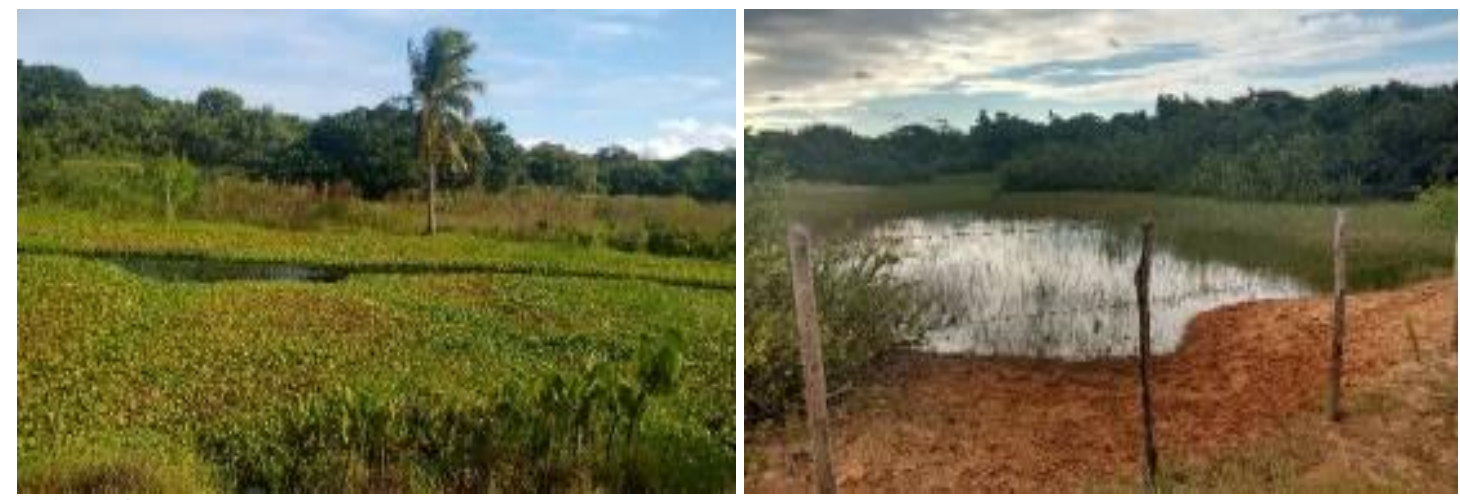

Figuras 03 e 04: Vegetação herbácea na superfície do rio Piranhas à esquerda e vegetação hidrófila em área de alagado à direita. Fonte: Acervo Próprio (2016).

No que diz respeito à ocupação antrópicas, sabe-se que é um fator exógeno que está em constante interação com os elementos naturais, quer de forma positiva ou negativa. Sabendo disso, cabe destacar os tipos de atividades praticadas às margens dos rios e lagoas situadas no município de Rio do Fogo/RN, ações estas que tem causado interferências negativas nesses ambientes.

Em Rio do Fogo/RN existem cinco lagoas, onde foram visitadas as lagoas da Cotia, Catolé e Mutuca, além do rio Punaú, Piranhas e Tatu, como outros rios e riachos sem toponímia. Cada uma dessas áreas possui dinâmicas e utilização antrópica diferenciadas, podendo-se destacar a privatização da lagoa da Cotia, a qual possui uma área a qual foi destinada à utilização turística.

Já na lagoa do Catolé, localizada próximo ao povoado Canto Grande foram feitos, canais de irrigação para a plantação de bananas, cultura que existe em boa parte da sua planície. Tal fato faz com que as margens deste corpo hídrico entre em processo de colmatagem, o que pode ocasionar a diminuição da área ou até mesmo a sua extinção (Figura 05) 


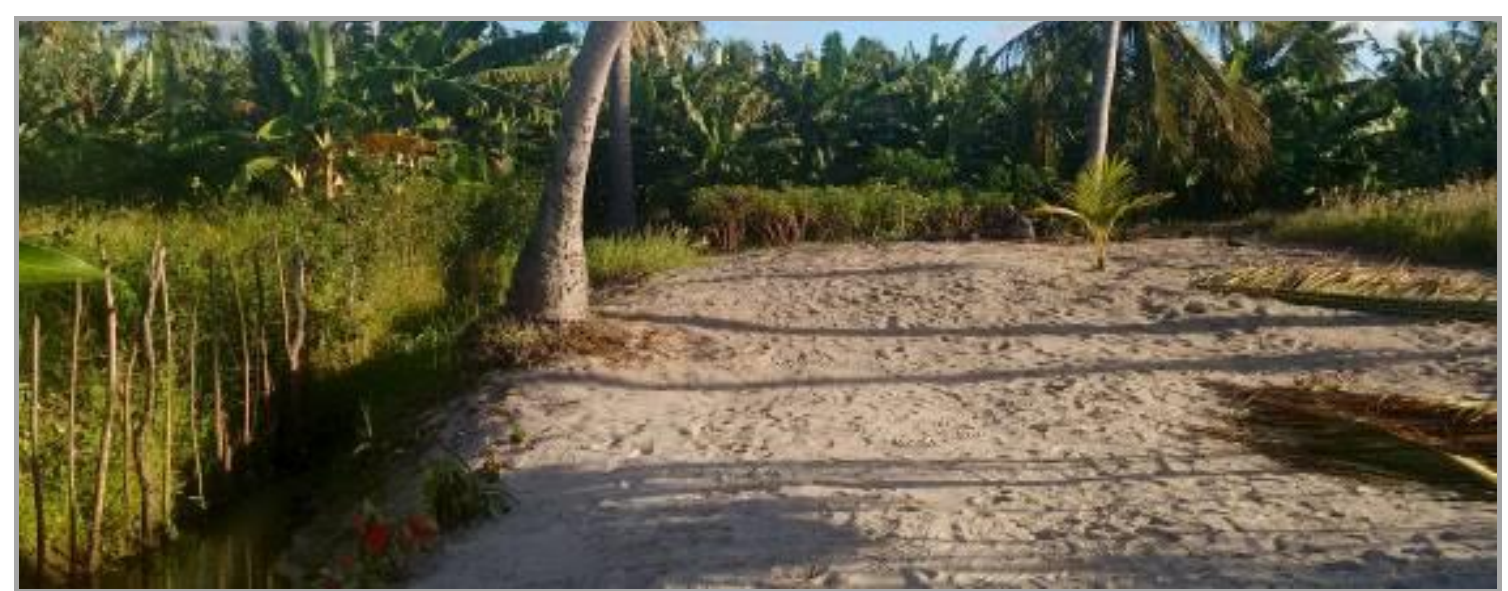

Figura 05: Plantação de bananas, próximo a Lagoa do Catolé. Fonte: Acervo do autor, 2016.

Com relação aos rios, na bifurcação entre o Punaú e Tatus, foi identificada a retificação de suas margens com o provável intuito de baixar o volume de água para plantação, visto que nas proximidades da área é notável a presença considerável de plantações de coco (Figura 06).

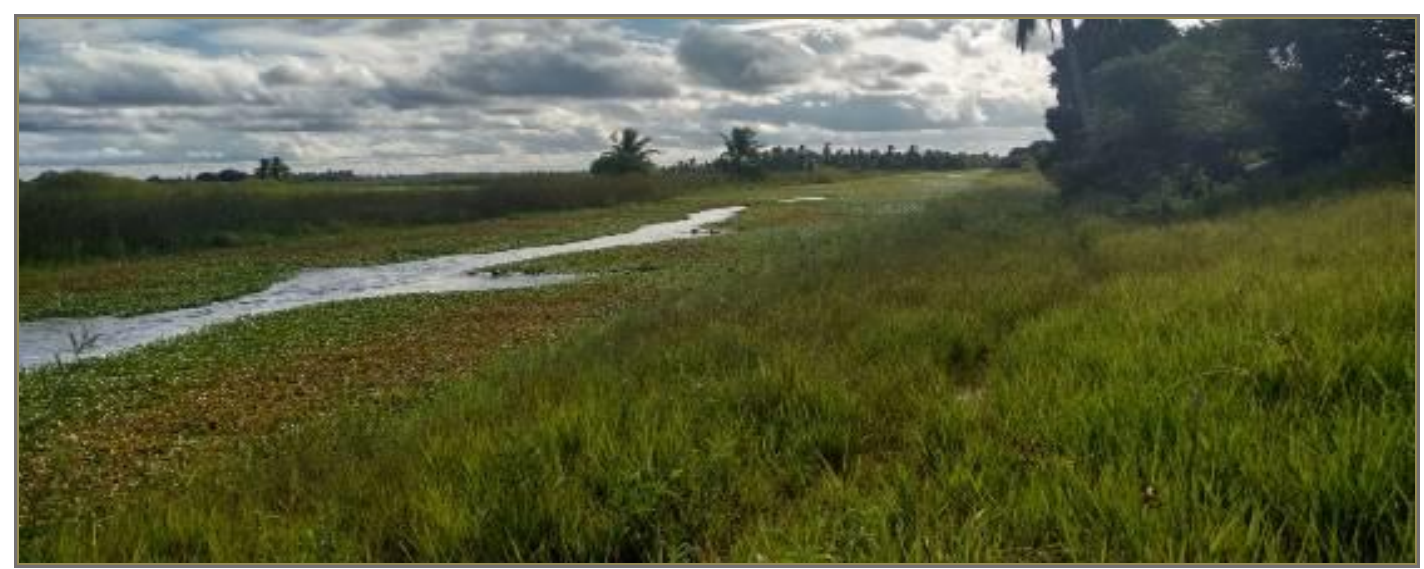

Figura 06: Retificação do rio Punaú. Fonte: Acervo da Pesquisa, 2016.

É importante destacar também a interação das Planícies Fluvial e Lacustre com os sistemas vizinhos, dentre os quais pode-se destacar neste trabalho, os Tabuleiros Costeiros e a Planície Costeira (Figura 07). Ambos têm consideráveis contribuições no que diz respeito à dinâmica sedimentológica, pedológica, hidrológica, litológica desses ambientes hídricos. Além disso, estes também possuem papel significativo na interface natural das outras unidades, fazendo com que haja interação e benefícios mútuos. 


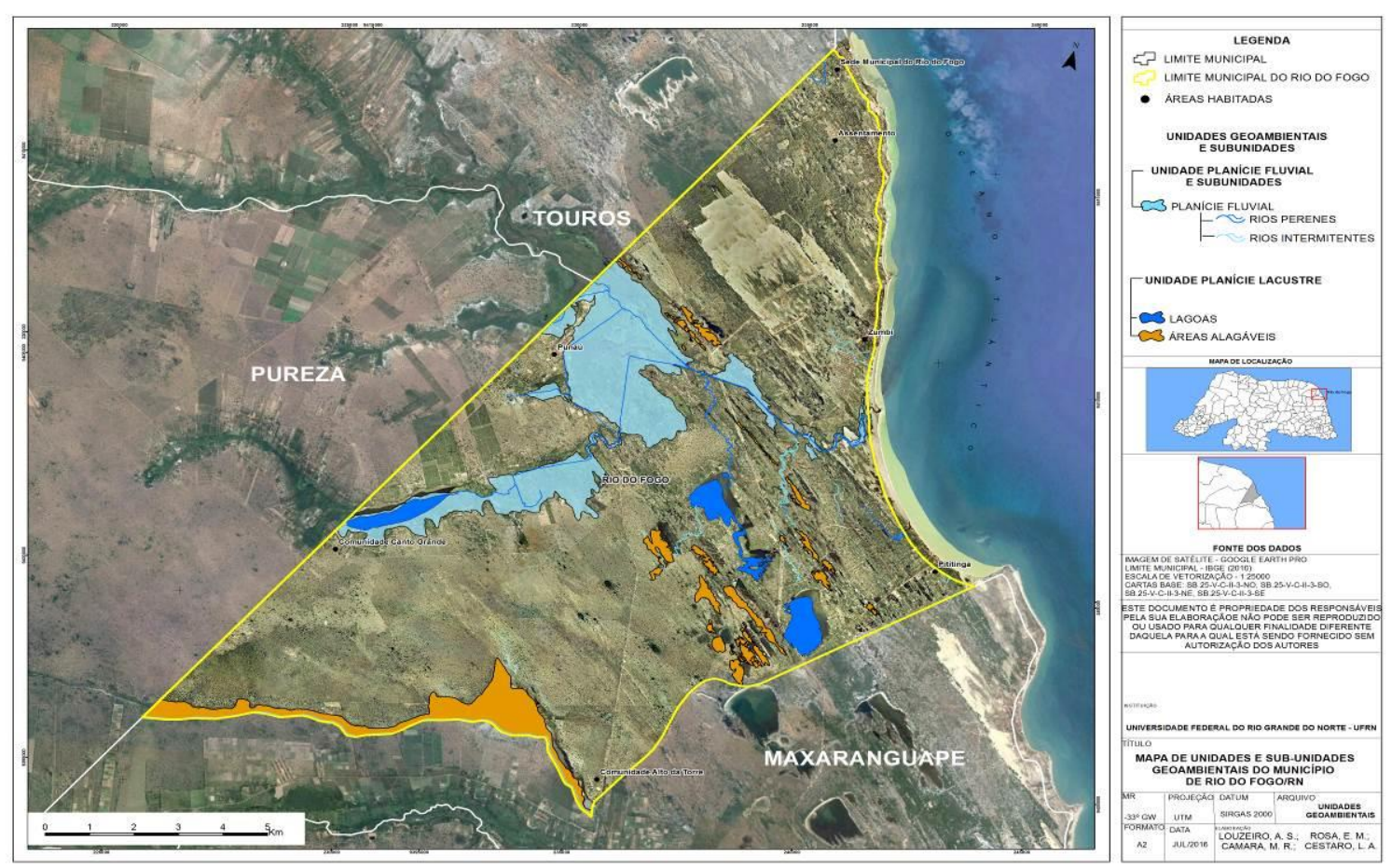

Figura 07: Mapa das unidades geoambientais no município do Rio do Fogo/RN. Fonte: Elaboração Própria, 2016.

No que diz respeito à interação da Planície Fluvial com as unidades Geoambientais vizinhas,

primeiramente destaca-se o contato com o Tabuleiro Costeiro, a qual é notável pela mudança abrupta no relevo entre um sistema e outro. Os rios conseguem provocar uma erosão acentuada no relevo, dissecando-o e formando vales mais extensos que vão desde a nascente do rio Pium e do rio das Piranhas no município de Pureza e adentrando nas porções sudoeste e oeste do Rio do Fogo/RN até próximo à Planície Costeira, na porção centro - leste. Essas rochas erodidas, por sua vez, enriquecem as águas dos rios de íons e sais minerais que são transportados pela corrente e depositados nas planícies de inundação, as tornando férteis e vegetadas.

O sistema tabuleiro costeiro possui relevo com as maiores altitudes do município, tornando assim o lençol freático bastante profundo se comparado aos outros sistemas. Além disso, também possui rochas muito friáveis e de alta porosidade, por essa razão o sistema lagunar é bem mais escasso, sendo encontrado afloramentos nas regiões mais próximas do contato com o sistema da Planície Costeira, na porção sudeste da área de estudo, devido à diminuição da altitude.

Já a interação entre as Planícies Fluvial e Costeira começa com a intensa diminuição da planície de inundação dos rios, que deve ocorrer principalmente pela composição mineral predominantemente arenosa e de origem eólica no ambiente costeiro, pois o quartzo é um material inerte, e por isso, extremamente resistente ao intemperismo químico provocado pela água dos rios. Logo, menos recursos para formação de solos férteis são depositados. 


\section{CONSIDERAÇÕES FINAIS}

As Planícies Fluvial e Lacustre são áreas de extrema dinâmica ambiental, seja com interação com os elementos de fator exógeno, seja endógeno. São ambientes recentes e por isso podem ser considerados instáveis, levando em consideração sua estrutura e o material formado. Pode-se inferir que nessas áreas, no município de Rio do Fogo, embora não seja identificado a ocupação antrópica intensa, esses ambientes vêm sendo explorados para irrigação em larga escala em áreas de cultivo. Tal fato pode ocasionar a colmatação das áreas de Planície Fluvial. Além disso, a utilização de água das Lagoas, de forma intensa e frequente, são fatores que ocasionam a redução da vazão do corpo hídrico, fato que pode prejudicar a dinâmica do ambiente.

Neste sentido, existe uma necessidade em analisar e avaliar o tipo e intensidade de atividade a ser implantada em qualquer unidade geoambiental, salientando aqui as unidades de ambientes hídricos, pois tem-se que considerar a composição pedológica, sedimentológica, cobertura vegetal, fatores hidrológicos, e principalmente de uso e ocupação humana. Sabendo disto, é possível identificar até que ponto as atividades antrópicas podem influenciar consideravelmente na dinâmica natural das Planícies e, desta forma, os fatores relacionados ao Planejamento Ambiental se apresentam como principais desenvolvedores de Políticas voltadas para a conservação dessas áreas.

\section{REFERÊNCIAS}

BURGER, M. I. Situação e Ações Prioritárias para a Conservação de Banhados e Áreas Úmidas da Zona Costeira. Porto Alegre: Anp, 1999. 60p. Disponível em: <http://www.anp.gov.br/brasilrounds/round8/round8/guias_r8/perfuracao_r8/Áreas_Prioritárias/Ban hados.pdf>. Acesso em: 23 jun. 2016.

CALDERANO FILHO, B. Análise Geoambiental de Paisagens Rurais Montanhosas da Serra do Mar utilizando Redes Neurais Artificiais. Tese de Doutorado - Geologia de Engenharia Ambiental - Universidade Federal do Rio de Janeiro, Instituto de Geociências. UFRJ. Rio de Janeiro, 2012. 322p.

INSTITUTO BRASILEIRO DE GEOGRAFIA E ESTATÍSTICA. Rio do Fogo/RN. Cidades@. 2016. Disponível em: <http://cidades.ibge.gov.br/xtras/perfil.php?lang=\&codmun=240895 \&search=\|infogr\%E1ficos:-informa\%E7\%F5es-completas>. Acesso em: jun. 2016.

LIMA, E. Q.; AMARAL, R. F. Vulnerabilidade da Zona Costeira de Pititinga/RN, Brasil. Mercator, Fortaleza, v. 12, n. 28, p. 141-153, 2013.

SANTOS, H. G. et al. Sistema Brasileiro de Classificação de Solos. 3 ed. rev. ampl. - Brasília, DF Embrapa, 2013. 440p. 
SALGADO, O. A.; JORDY FILHO, S.; GONÇALVES, L. M. C. Vegetação. Projeto RADAM BRASIL. Folhas SB 24/25. Pg 485-544. Jaguaribe/Natal. Rio de Janeiro, 1981.

SOTCHAVA, V. B. O Estudo de Geossistemas. Instituto de Geografia. USP, São Paulo: Ed. Lunar, 1977. 51p.

SOUZA, C. G.; VIANA, C. D. B.; WAKE, M., et al. Pedologia. Projeto RADAM BRASIL. Folhas SB 24/25. Pg 349-484. Jaguaribe /Natal. Rio de Janeiro, 1981.

SUGUIO, K. Dicionário de Geologia Sedimentar e Áreas Afins. Rio de Janeiro: Bertrand Brasil, 1998. $1222 \mathrm{p}$.

TUNDISI, José G.; MATSUMURA-TUNDISI, T. Limnologia. São Paulo: Oficina de Textos, 2008. 631p.

Recebido em: 14/08/2016

Aceito para publicação em: 01/10/2016 